\title{
Visualization of giant virus particles using BONCAT labeling and STED microscopy
}

\author{
Mónica Berjón-Otero ${ }^{1}$, Sarah Duponchel ${ }^{1}$, Thomas Hackl ${ }^{1}$ and Matthias Fischer ${ }^{1 *}$ \\ ${ }^{1}$ Max Planck Institute for Medical Research, Heidelberg, Germany \\ *correspondence to: Matthias Fischer, MPI for Medical Research, Jahnstraße 29, 69120 Heidelberg, \\ Germany, +49-(0)6221-486506; mfischer@mr.mpg.de
}

\section{Significance}

Giant DNA viruses are the dominant class of protist-infecting viruses, yet the vast majority of described giant virus-protist systems remain uncultured. One of the better studied cultured systems is composed of the stramenopile Cafeteria burkhardae (previously $C$. roenbergensis), the giant Cafeteria roenbergensis virus (CroV) and the virophage mavirus. $C$. burkhardae is a widespread marine phagotrophic protist that plays an important role in regulating bacterial populations. In addition to being grazed upon by larger zooplankton, $C$. burkhardae populations are controlled by the lytic giant virus CroV. In turn, CroV is parasitized by the virophage mavirus that increases host population survival in the presence of $\mathrm{CroV}$ and forms a mutualistic symbiosis with its host. Despite being of fundamental ecological and evolutionary interest, this tripartite host-virus-virophage system suffers from a lack of molecular tools. Here, we show that CroV particles can be fluorescently labeled and imaged by super-resolution microscopy. To achieve this we established robust procedures for analyzing protist and viral populations and implemented the use of bioorthogonal noncanonical amino acid tagging (BONCAT) in a marine unicellular flagellate.

\begin{abstract}
Giant DNA viruses of the phylum Nucleocytoviricota are being increasingly recognized as important regulators of natural protist populations. However, our knowledge of their infection cycles is still very limited due to a lack of cultured virus-host systems and molecular tools to study them. Here, we apply bioorthogonal noncanonical amino acid tagging (BONCAT) to pulse label the marine heterotrophic flagellate Cafeteria burkhardae during infection with the lytic giant virus CroV. In absence of CroV, we report efficient incorporation of the L-methionine analog L-azidohomoalanine (AHA) into newly synthesized proteins of the methionine prototrophic $C$. burkhardae. During CroV infection, AHA was predominantly found in viral proteins, and single CroV virions were imaged with stimulated emission depletion (STED) super-resolution microscopy. CroV particles incorporated AHA with $95-100 \%$ efficiency while retaining their infectivity, which makes BONCAT/STED a powerful tool to study viral replication cycles in this ecologically relevant marine bacterivore.
\end{abstract}

Keywords: Cafeteria roenbergensis virus; CroV; Giant virus; Cafeteria burkhardae; bioorthogonal noncanonical amino acid tagging; BONCAT; L-azidohomoalanine; AHA. 


\section{Introduction}

Cafeteria roenbergensis is a marine unicellular heterotrophic biflagellated protist with a cell diameter of $2 \mu \mathrm{m}$ to $6 \mu \mathrm{m}$ (Fenchel and Patterson, 1988; O'Kelly and Patterson, 1996). It belongs to the order Bicosoecida (Stramenopiles) and is widely distributed in marine environments such as surface waters, deep sea sediments, and hydrothermal vents (Atkins et al., 2000; Scheckenbach et al., 2005). As bacterivores, Cafeteria flagellates play an important role in carbon transfer and nutrient recycling (Boenigk and Arndt, 2002; Pernthaler, 2005). Recently, many of the circulating $C$. roenbergensis strains have been reclassified as C. burkhardae based on 18S rDNA analysis (Schoenle et al., 2020), including the strains used in this study. Studies on Cafeteria sp. have been mainly focused on bacterial grazing and its ecological impact (Otto et al., 1997; Boenigk and Arndt, 2000; Zubkov and Sleigh, 2000; De Corte et al., 2019), whereas the molecular biology of this Stramenopile remains largely unknown. We recently published the first genome assemblies for $C$. burkhardae which showed that the $35 \mathrm{Mbp}$ genome is mostly diploid (Hackl et al., 2020). In the wild, Cafeteria populations are modulated by their interactions with viruses (Massana et al., 2007). Two of these, Cafeteria roenbergensis virus (CroV) and mavirus, have been isolated from Cafeteria cultures in the past, revealing a fascinating tripartite host-virus-virophage system (Garza and Suttle, 1995; Fischer et al., 2010; Fischer and Suttle, 2011).

CroV is a lytic giant virus of the family Mimiviridae (Fischer et al., 2010). CroV particles are $300 \mathrm{~nm}$ in diameter and composed of an outer protein shell with icosahedral symmetry, an internal lipid membrane, and a proteinaceous core (Xiao et al., 2017). The $\approx 700$ kilobase pair double-stranded DNA genome encodes more than 500 predicted proteins (Fischer et al., 2010, 2014) including DNA replication and transcription machineries, which enables CroV to replicate in the host cytoplasm, in the so-called virion factory, similar to other mimiviruses and also poxviruses (Schramm and Krijnse-Locker, 2005; Suzan-Monti et al., 2007; Mutsafi et al., 2010). Although CroV encodes some translation components, it lacks ribosomal proteins and therefore depends on host translation. Newly synthesized CroV particles are released as early as 5-6 hours post infection (hpi), while the majority of extracellular virions appear during host cell lysis at 15-22 hpi (Taylor et al., 2018).

The second virus in the tripartite Cafeteria system is the virophage mavirus of the family Lavidaviridae, an obligate parasite that depends on the presence of the CroV for its propagation (Fischer and Suttle, 2011; Krupovic et al., 2016). During a co-infection of C. burkhardae, mavirus severely reduces CroV particle production thereby protecting the still CroV-uninfected part of the host population (Fischer and Hackl, 2016). In addition, mavirus enters C. burkhardae cells independently of CroV and integrates its genome into the host genome, where virophage gene expression does not occur until the cell, or one of its descendants carrying the endogenous mavirus, is infected with CroV. Once reactivated by CroV, mavirus replicates and CroV and mavirus particles are released by cell lysis (Fischer and Hackl, 2016; Berjón-Otero et al., 2019; Duponchel and Fischer, 2019). Mavirus may thus provide an anti-viral defense for $C$. burkhardae populations against the spread of CroV.

Currently, the lack of molecular tools hampers a deeper mechanistic understanding of this tripartite system. We, therefore, explored bioorthogonal noncanonical amino acid tagging (BONCAT) as a fast and easy technique for protein labeling during viral infection. BONCAT is based on the incorporation of a 
noncanonical amino acid into nascent polypeptide chains during protein translation (Kiick et al., 2002; Dieterich et al., 2006). One of these noncanonical amino acids is L-azidohomoalanine (AHA), a nontoxic and water-soluble analog of methionine containing an azido moiety. Thus, when AHA is present in the culture medium, cellular uptake and loading by methionyl-tRNA synthetase lead to AHA incorporation into newly synthesized proteins. AHA-containing proteins can then be purified via an alkyne-bearing biotinylated tag, or coupled to a fluorophore via $\mathrm{Cu}(\mathrm{I})$-catalyzed azide alkyne cycloaddition (CuAAC), also known as "click chemistry" or Click-iT ${ }^{\circledR}$ (Rostovtsev et al., 2002; Tornøe et al., 2002; Zhang et al., 2017). To maximize the incorporation rates of the noncanonical amino acid, this technique is often applied in methionine auxotrophic organisms or cell culture systems such as mammalian cells (Dieterich et al., 2007; Zhang et al., 2017). However, in recent years, efficient AHA incorporation has been demonstrated in natural samples (Hatzenpichler et al., 2014; Leizeaga et al., 2017). BONCAT can also be used to label viral proteins when AHA or another noncanonical amino acid is added during viral infection (Banerjee et al., 2011; Huang et al., 2017; Wang et al., 2020).

Here we show successful BONCAT labeling of newly synthesized proteins in C. burkhardae, a eukaryotic organism containing essential genes for methionine biosynthesis. When this protist is infected with CroV, AHA is incorporated in viral proteins allowing the visualization of giant virus particles with high-resolution microscopy. AHA incorporation in CroV particles is highly efficient (95-100\%) and AHA does not impair the infectivity or virion yield of CroV. Our results prove that antibody-free metabolic labeling combined with super-resolution microscopy is an effective method to visualize giant viruses by fluorescence microscopy. The protocols described here provide the basis for future microscopy studies of $C$. burkhardae and its viruses.

\section{Results and discussion}

\section{Essential methionine biosynthesis genes are present and transcribed in C. burkhardae}

Because high endogenous methionine levels can impair efficient BONCAT labeling with methionine analogs such as AHA, methionine auxotrophic organisms are preferably used for this technique (Wisse et al., 2017; Zhang et al., 2017). Therefore we first examined the methionine biosynthesis coding potential in C. burkhardae using the recently published genome assembly of C. burkhardae strain RCC970-E3 (Hackl et al., 2020). We queried all predicted protein sequences encoded by $C$. burkhardae against the methionine pathway proteins as described in the diatom Thalassiosira pseudonana (Bromke and Hesse, 2015). BLAST analysis revealed homologs for all genes in question (Fig. 1A and Table S1). Interestingly, three of these enzymes (aspartate kinase, GenBank acc. numbers KAA0156511 and KAA0162106; homoserine acetyltransferase, KAA0152884 and KAA0165906; methionine synthase, KAA0150236 and KAA0158901) were represented by two separate genes each in the $C$. burkhardae genome. The presence of two non-homologous aspartate kinases was also reported in T. pseudonana (Bromke and Hesse, 2015), also two methionine synthases were found in other eukaryotes such as Phaeodactylum tricornutum (Helliwell et al., 2011), however non-homologous homoserine acetyltransferases, to the best of our knowledge, have so far only been described in bacteria (Ferla and Patrick, 2014).

An essential step in methionine biosynthesis is homoserine activation, which can be carried out by transfer of a phosphate group (Bartlem et al., 2000), a O-succinyl group (Born and Blanchard, 1999), or an $O$-acetyl group (Goudarzi and Born, 2006) to the $\gamma$-hydroxyl group of homoserine. Our 
computational analysis did not identify homologs of a homoserine kinase or a homoserine $O$-succinyltransferase. Instead, we found two putative homologs of a homoserine $O$-acetyltransferase suggesting that, in $C$. burkhardae, homoserine is activated through the addition of an $O$-acetyl group (Fig. $1 \mathrm{~A}$ and Table S1). The activated $O$-acetyl-homoserine is then converted to homocysteine, either directly or with cystathionine as an intermediate (Fig. 1A). However, the high sequence similarities between cystathionine- $\gamma$-synthase, cystathionine- $\beta$-lyase and cysteine-synthase made it difficult to predict which of the five candidate genes (KAA0166696, KAA0162384, KAA0146633, KAA0161056, KAA0169545) encoded which enzymatic activity, as previously discussed for cystathionine synthases and lyases in T. pseudonana (Bromke and Hesse, 2015). Nevertheless, genome analysis strongly suggests that C. burkhardae encodes a complete methionine biosynthesis pathway.

To test if the identified genes were transcribed, we performed reverse-transcription PCR on three of them (KAA0152884, KAA0165906 and KAA0166696) (Fig. 1B). KAA0152884 and KAA0165906 are predicted to encode a homoserine acetyltransferase, the key enzyme for homoserine activation, which is absent in methionine auxotrophs (Finkelstein, 1990; Ferla and Patrick, 2014; Bromke and Hesse, 2015). The gene product of KAA0166696 is predicted to act downstream of homoserine activation in methionine biosynthesis. As a control, we used the aspartyl tRNA synthetase (AspRS) gene whose expression has been demonstrated previously (Fischer and Hackl, 2016). We found that all tested genes were expressed in actively growing $C$. burkhardae cells (Fig. 1B). Based on the presence and expression of all essential methionine biosynthesis genes, we conclude that $C$. burkhardae is a methionine prototrophic organism.

A

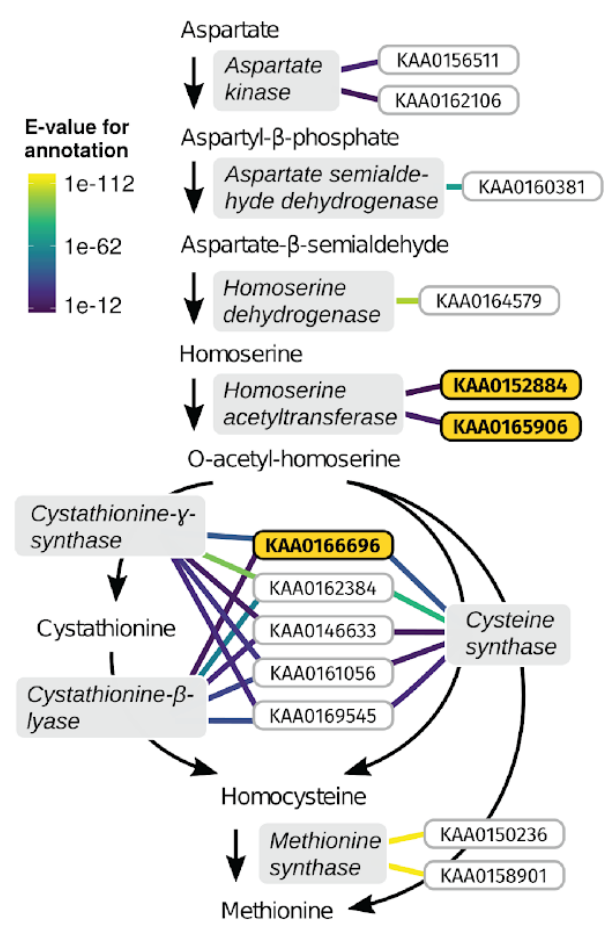

Figure 1. The inferred methionine biosynthesis pathway in $C$. burkhardae. (A) Gene products of $C$. burkhardae predicted to function in methionine biosynthesis are listed with their GenBank accession numbers (framed boxes). Lines connecting $C$. burkhardae proteins to enzymatic functions are color-coded according to their E-values against the EggNOG database. The expression of three key genes (bold, orange) was confirmed with reverse-transcription PCR. (B) Expression of genes KAA0152884, KAA0165906 and KAA0166696 in C. burkhardae. Shown are the RT-PCR products obtained from three independent $C$. burkhardae cultures (labeled A-C), including the constitutively expressed aspartyl-tRNA synthetase gene (AspRS) as a positive control. Lanes 4, 8, 12 and 16 correspond to no-template controls.

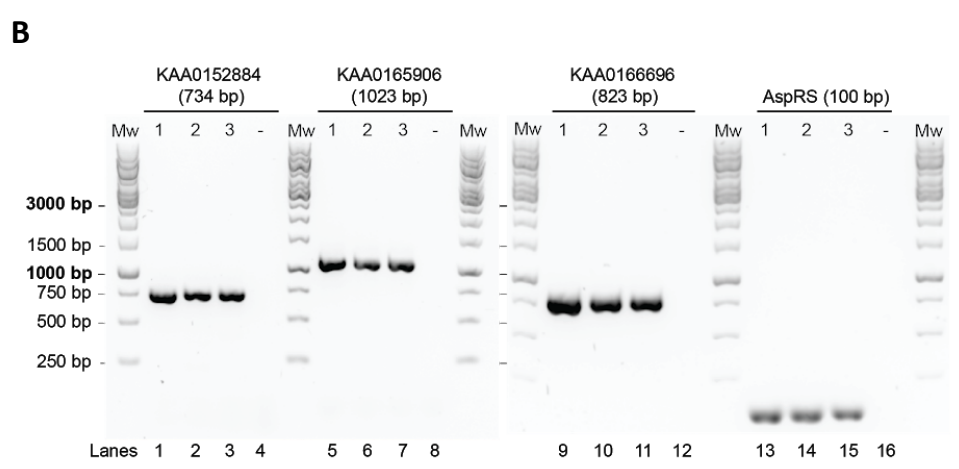




\section{Density-based removal of food bacteria from cultures of $C$. burkhardae}

In order to reduce potential background signal in our assays from the mixed bacterial community that is present as a food source in C. burkhardae cultures, we used a $10 \% / 20 \%(\mathrm{w} / \mathrm{v})$ iodixanol density cushion to separate bacteria from flagellate cells. Bacteria will penetrate the $20 \%$ iodixanol layer and pellet during centrifugation, whereas $C$. burkhardae cells collect at the $10 \%-20 \%$ iodixanol interphase. To evaluate the effectiveness of this process, cells from an untreated Cafeteria culture were compared to cells extracted from the $10 \%-20 \%$ iodixanol interphase. Cells were fixed and immobilized on Poly-L-Lysine-treated coverslips (PLL-treated), stained with 4' ,6-diamidino-2-phenylindole (DAPI), and imaged with a fluorescence microscope. In untreated cultures, the bacterial DAPI fluorescence impaired the visualization of $C$. burkhardae DNA (Fig. S1A). When the culture was purified via iodixanol density cushion centrifugation, the bacterial concentration decreased sufficiently allowing the identification of individual cells of $C$. burkhardae (Fig. S1A). However, not all bacteria were removed during the procedure, probably owing to the heterogeneous species composition of the bacterial population, with some bacteria exhibiting buoyant densities similar to that of $C$. burkhardae.

We used flow cytometry to quantify the remaining bacteria in $C$. burkhardae cultures before and after density cushion centrifugation. As shown in Fig. S1B, bacterial populations can be distinguished from $C$. burkhardae cells in scatter plots. Gating and quantification (Table S2) of bacterial populations indicated that $20 \%-50 \%$ of bacteria from the original culture are still retained after purification, hence iodixanol density cushion centrifugation removed $50-80 \%$ of the bacteria (Fig. S1B) without impacting $C$. burkhardae populations. Thus, the procedure is adequate for reducing the bacterial background. Moreover, the additional centrifugation steps during cell preparation for fluorescent microscopy will further remove bacteria leading to levels that allow clear imaging of $C$. burkhardae cells.

\section{AHA is efficiently incorporated into $C$. burkhardae proteins}

To test for AHA uptake in C. burkhardae, we incubated cultures that had been purified by density cushion centrifugation with different AHA concentrations for four hours. AHA incorporation in $C$. burkhardae proteins was initially analyzed by polyacrylamide gel electrophoresis (PAGE). Given the lack of protocols for protein extraction from $C$. burkhardae, we first tested chemical lysis conditions with different concentrations of the following nonionic detergents: Igepal ${ }^{\circledR}, \operatorname{Triton}^{\mathrm{TM}} \mathrm{X}-100$, and NP-40. The best results were obtained with $1 \%$ Igepal ${ }^{\circledR}$ (data not shown). Thus, after AHA incubation, C. burkhardae cells were incubated in a buffer containing $1 \%$ Igepal $^{\circledR}$ and the total and soluble protein fractions were loaded on a $12 \%$ SDS-PA gel to assess cell lysis. No differences were found between Coomassie-stained total and soluble fractions, indicating efficient lysis (Fig. S2). Next, soluble AHA-containing proteins were labeled by Click-iT ${ }^{\circledR}$ with tetramethylrhodamine alkyne (TAMRA) dye and analyzed via SDS-PAGE. Coomassie staining confirmed that the same amount of protein was loaded in all the lanes, consequently, no differences are observed between samples (Fig. 2A, lanes 1-5). TAMRA detection showed that $C$. burkhardae cell lysates contained AHA-labeled proteins, when AHA concentrations of $0.25 \mathrm{mM}$ to $2 \mathrm{mM}$ were used (Fig. 2A lanes $2^{\prime}-5^{\prime}$ ). TAMRA intensity was only slightly higher for $1 \mathrm{mM}$ of AHA (Fig. 2A lane 4') compared to the other AHA concentrations tested (45528 arbitrary unit [AU] counts for $0.25 \mathrm{mM}$ AHA, $45600 \mathrm{AU}$ counts for $0.5 \mathrm{mM} \mathrm{AHA}, 54344$ AU counts for $1 \mathrm{mM} \mathrm{AHA}$, and 48096 $\mathrm{AU}$ counts for $2 \mathrm{mM} \mathrm{AHA}$ ) which could be caused by small differences during gel loading. As expected, 
bioRxiv preprint doi: https://doi.org/10.1101/2020.07.14.202192; this version posted July 14, 2020. The copyright holder for this preprint (which was not certified by peer review) is the author/funder, who has granted bioRxiv a license to display the preprint in perpetuity. It is made available under aCC-BY-NC-ND 4.0 International license.

the strongest Coomassie bands did not match the strongest TAMRA bands. This is due to Coomassie intensity being proportional to the amount of loaded protein while AHA incorporation depends on the number of methionine residues per protein.

A

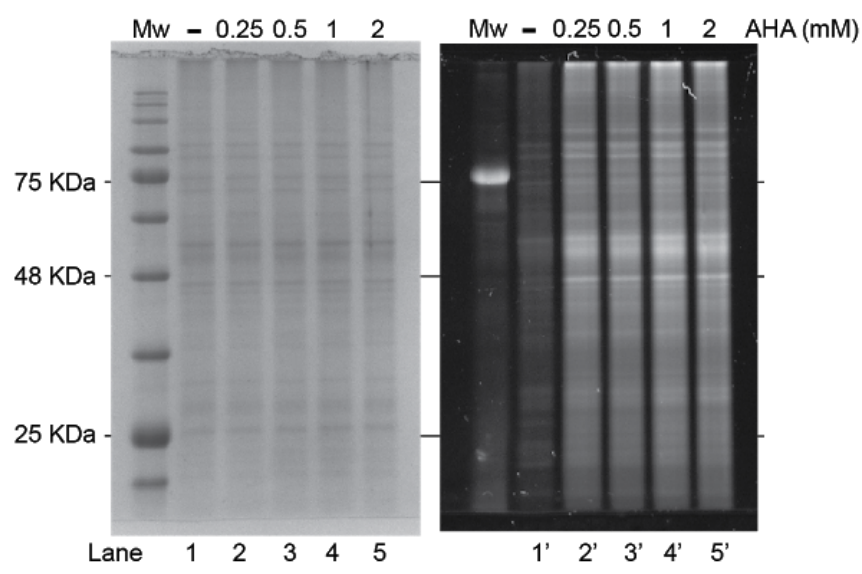

Figure 2. Incorporation of AHA in C. burkhardae proteins. (A) SDS-PAGE of soluble proteins extracted from $6 \times 10^{6} \mathrm{C}$. burkhardae cells that were incubated with different concentrations of AHA. Gels were first stained with Coomassie (lanes 1-5) and then tested for the presence of AHA via coupling and excitation of a TAMRA fluorophore (lanes 1'-5'). (B) Confocal microscopy of $C$. burkhardae cells incubated with different concentrations of AHA. AHA residues were coupled to Alexa Fluor 594 and DNA was stained with DAPI. Areas outlined by white boxes are shown at higher magnification in the panels on the right.

B

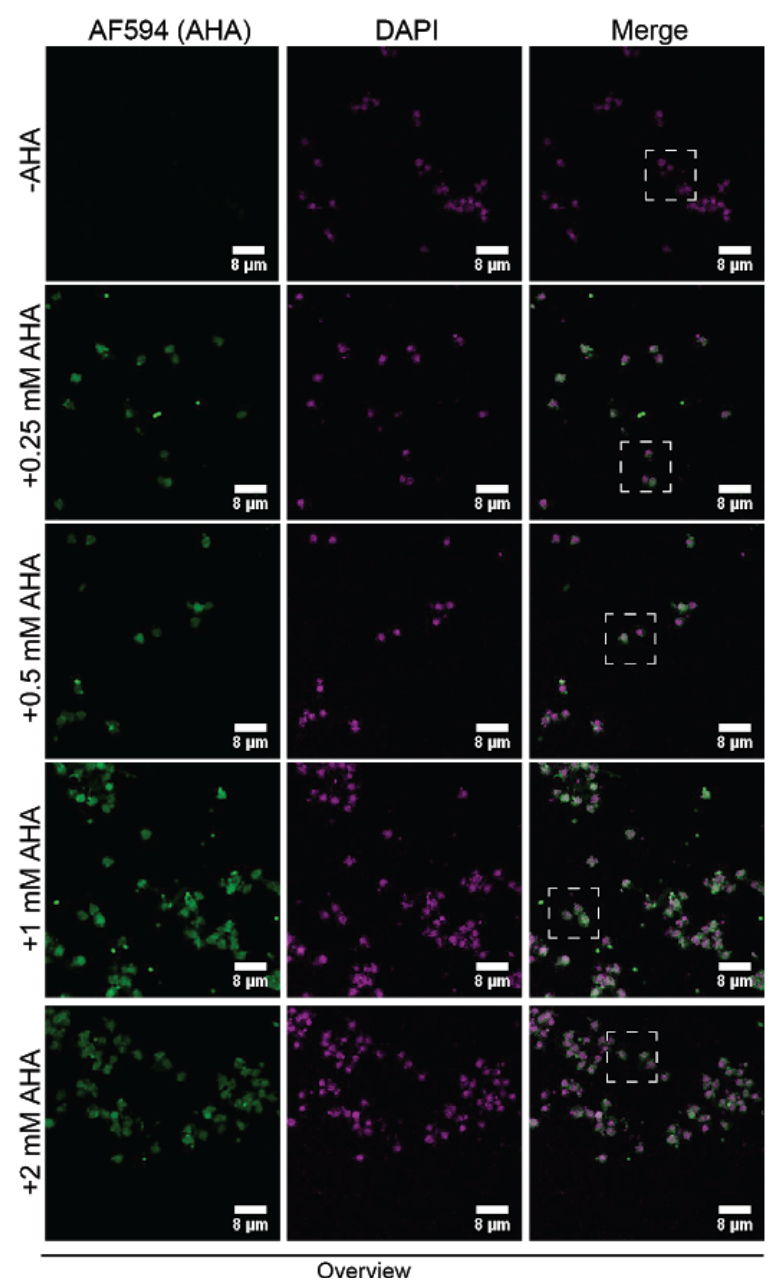

AF594 (AHA)

DAPI
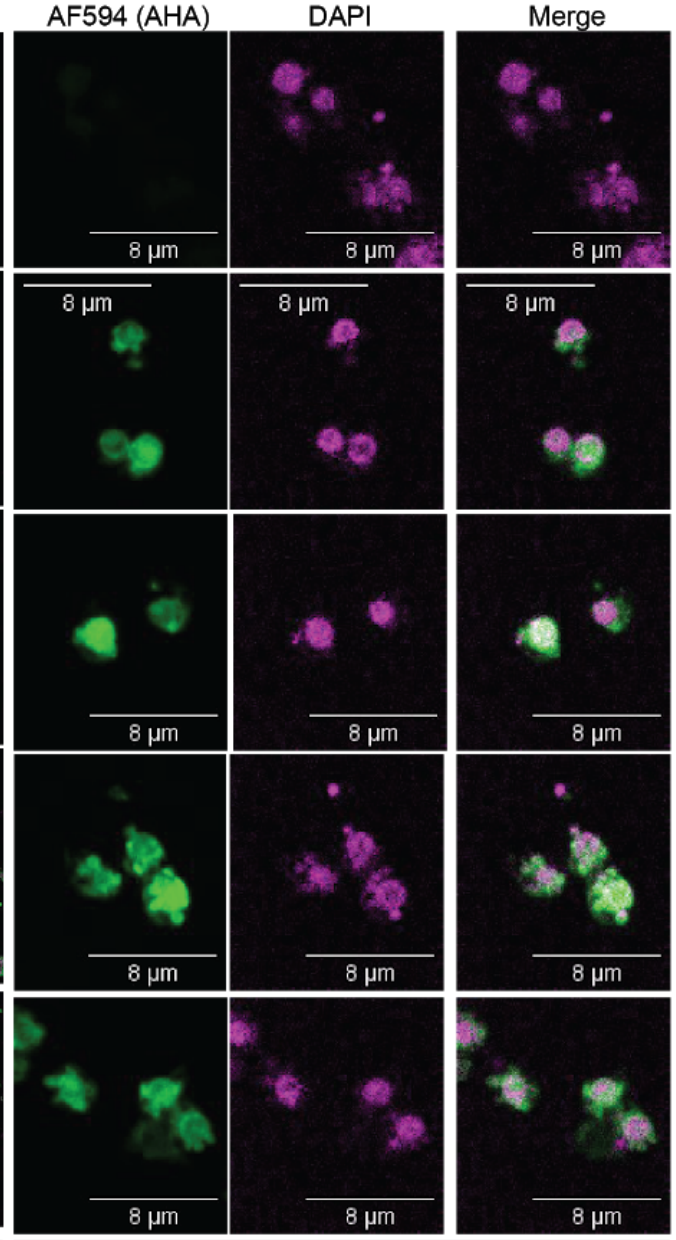

Close-ub 
In order to confirm that the AHA signal colocalized with C. burkhardae instead of residual bacteria, we labeled AHA residues with Alexa Fluor 594 (AF594) alkyne dye and analyzed cells using confocal microscopy. With all AHA concentrations tested, $100 \%$ of $C$. burkhardae cells showed a fluorescent signal in the AF594 channel (Fig. 2B), which indicates that AHA can replace methionine during protein synthesis in this protist. Most of the AHA-linked fluorescence signal was located around the nucleus and the mitochondria, which corresponds to the subcellular localization of protein biosynthesis. The highest signal was again obtained with $1 \mathrm{mM}$ of AHA (fluorescence intensity $161 \mathrm{AU}$ counts vs $126 \mathrm{AU}$ counts for $0.25 \mathrm{mM}$ AHA, $105 \mathrm{AU}$ counts for $0.5 \mathrm{mM}$ AHA and $123 \mathrm{AU}$ counts for $2 \mathrm{mM} \mathrm{AHA}$ ). However, the differences between AHA concentrations were small so that we decided to perform subsequent experiments with $0.5 \mathrm{mM}$ of AHA in order to minimize potential stress for the cells.

\section{AHA is preferably incorporated into viral proteins during CroV infection}

Next, we tested AHA incorporation into viral proteins during a $C$. burkhardae infection with the giant DNA virus CroV. We infected a C. burkhardae culture with CroV at a multiplicity of infection (MOI) of 2 and, after $1 \mathrm{~h}$ of incubation, removed the bulk of bacteria and free CroV particles by centrifugation on a $10-20 \%(w / v)$ iodixanol density cushion. As a control, we used a non-infected culture treated identically. After density cushion centrifugation, flagellate cells were resuspended in $\mathrm{f} / 2$ medium with $0.5 \mathrm{mM}$ AHA or dimethyl sulfoxide (DMSO) (AHA-negative control) starting at 3 or $7 \mathrm{hpi}$. After $4 \mathrm{~h}$ of incubation with AHA, cells were harvested and lysed at 7 and $11 \mathrm{hpi}$, respectively. We analyzed the resulting protein extracts on a $12 \%$ SDS-PAGE stained with Coomassie Brilliant Blue R-250 (Fig. S3). The banding patterns were nearly identical between soluble and total fractions, indicating efficient cell lysis. Interestingly, only one Coomassie band was detected in the CroV-infected sample after $7 \mathrm{hpi}$ that was not present in the uninfected sample (Fig. S3, arrow). An additional band appeared at $11 \mathrm{hpi}$ (Fig. S3, asterisk). These two bands were identified by mass spectrometry as the major capsid protein CroV342 and the major core protein CroV332, respectively (Table S3). They are the two most abundant structural proteins in the CroV virion (Fischer et al, 2014) and good indicators for a productive CroV infection. Additional differences between infected and uninfected samples, as well as between $7 \mathrm{hpi}$ and $11 \mathrm{hpi}$ samples, were observed when we visualized AHA-containing proteins via TAMRA fluorescence (Fig. 3A, lanes 1'-4' and $\left.7^{\prime}-10^{\prime}\right)$. To compare these banding patterns directly with the CroV virion proteome, a protein lysate extracted from purified CroV particles is shown in lanes 5 and 6 of Fig. 3A. Several of these proteins were identified by mass spectrometry as CroV proteins (Figure 3A bands A to L, Table S3). Most of the proteins synthesized between $3 \mathrm{hpi}$ and $7 \mathrm{hpi}$ are probably non-structural CroV proteins because the banding pattern at $7 \mathrm{hpi}$ differs from both the uninfected condition as well as from the purified CroV particle proteins (Fig. 3A lane $4^{\prime}$ vs lanes $2^{\prime}$ and 5). At $11 \mathrm{hpi}$, the TAMRA banding pattern resembles the Coomassie pattern of the CroV virion proteome (Fig. 3A lanes 10' and 6), suggesting that most of the proteins synthesized in infected cells between 7 and $11 \mathrm{hpi}$ are CroV virion components. 
bioRxiv preprint doi: https://doi.org/10.1101/2020.07.14.202192; this version posted July 14, 2020. The copyright holder for this preprint (which was not certified by peer review) is the author/funder, who has granted bioRxiv a license to display the preprint in perpetuity. It is made available under aCC-BY-NC-ND 4.0 International license.

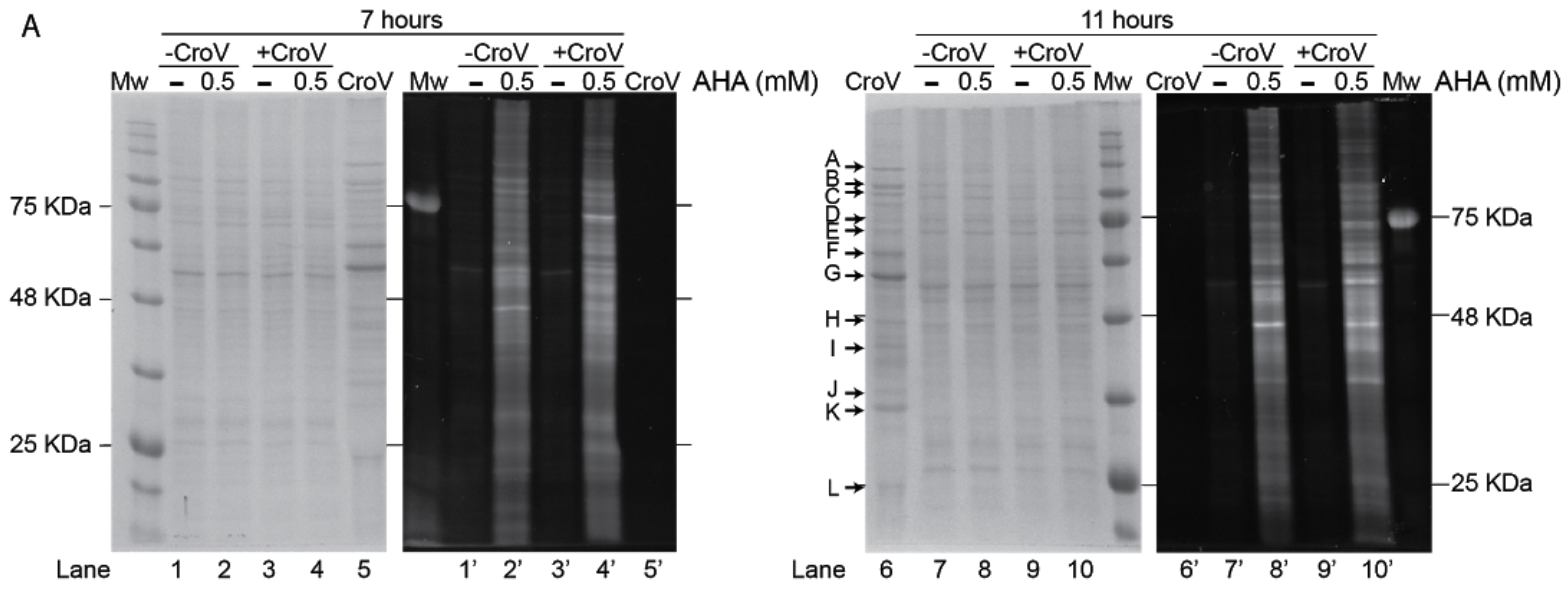

B

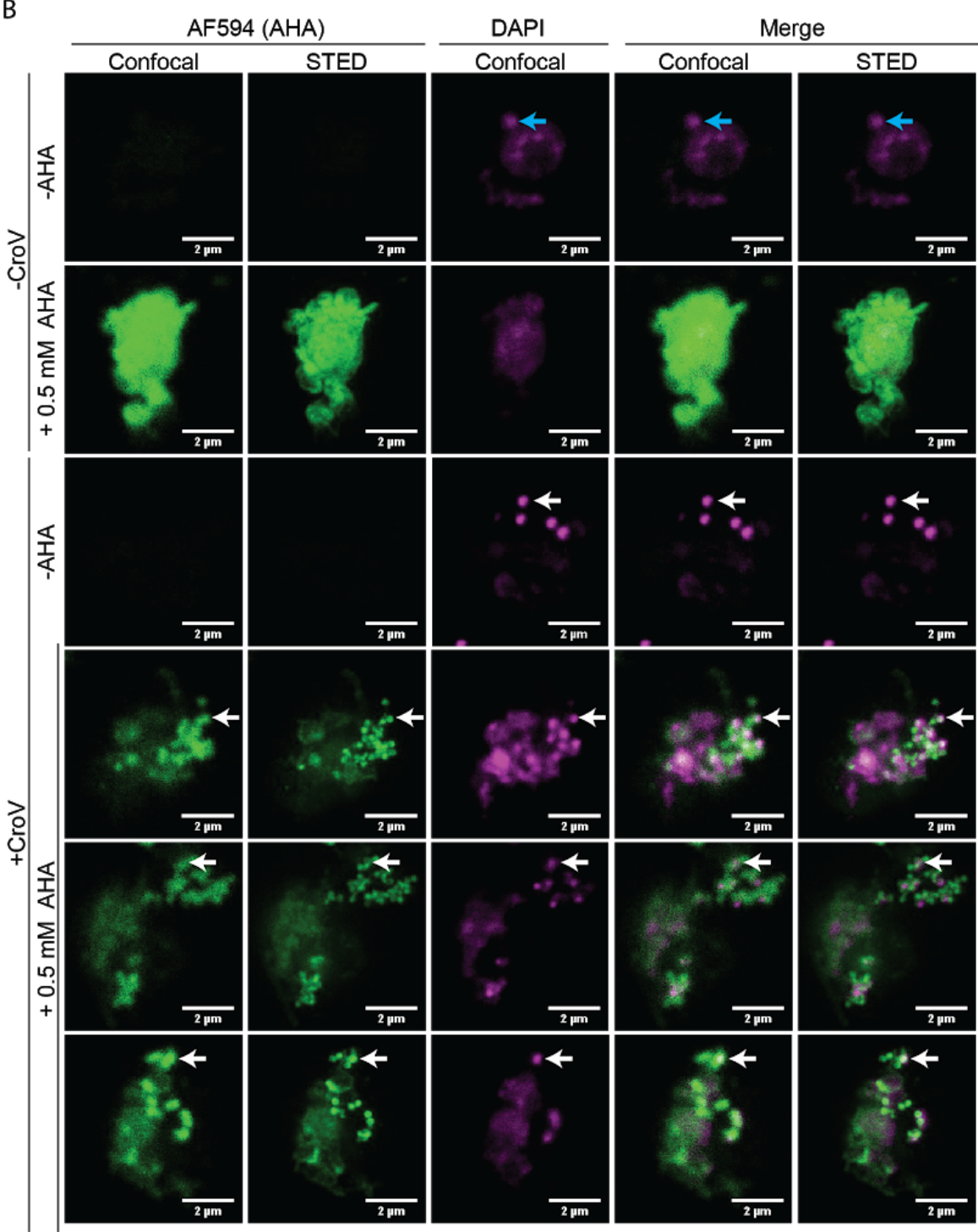

Figure 3. AHA incorporation during CroV infection. (A) SDS-PAGE of soluble proteins extracted from $6 \times 10^{6} \quad C$. burkhardae cells that were either uninfected or infected with CroV, and incubated with or without AHA for four hours prior to harvesting at $7 \mathrm{hpi}$ or $11 \mathrm{hpi}$. Gels were first stained with Coomassie (lanes 1-10) and then tested for the presence of AHA via coupling and excitation of a TAMRA fluorophore (lanes $\left.1^{\prime}-10^{\prime}\right)$. Proteins extracted from purified CroV particles are shown in lanes 5 and 6 , and bands that were analyzed by mass spectrometry are indicated by arrows A-L. (B) Confocal and STED microscopy of CroV-infected and non-infected C. burkhardae cells incubated with or without AHA. Cells were harvested at $7 \mathrm{hpi}$, AHA-containing proteins visualized by AF594 coupling and DNA stained with DAPI. White arrows indicate AF594 and DAPI signals of putative CroV particles, blue arrows depict putative mitochondria. 
We then coupled the fluorescent dye AF594 to AHA moieties using Click-i ${ }^{\circledR}$ and analyzed uninfected and CroV-infected cells ( $7 \mathrm{hpi}$ ) by confocal microscopy. In uninfected cells, the AF594 signal was located around the nuclear and mitochondrial DAPI signal (DNA) (Fig. 3B). However, when C. burkhardae cells were infected with CroV, the AF594 signal overlapped largely with a brighter DAPI signal that drowned out the weaker nuclear and mitochondrial signals (Fig. 3B). The most intense DAPI spots had a diameter of $\approx 300 \mathrm{~nm}$, which equals the diameter of a CroV capsid (Xiao et al., 2017). In contrast to the well-defined DAPI structures, the AF594 signal obtained by confocal microscopy was rather diffuse (Fig. 3B). We, therefore, analyzed the same samples with Stimulated Emission Depletion (STED) microscopy, which resolved AF594 fluorescence into distinct dots that overlapped with the DAPI signal and had a diameter of 200-300 nm, strongly suggesting that they corresponded to CroV particles (Fig. 3B). Whereas all distinct DAPI dots had a matching AF594 signal, some AF594 dots were DAPI-negative. This indicates that the highest concentration of AHA-containing proteins is present in newly synthesized CroV particles, but not all particles present at $7 \mathrm{hpi}$ contained DNA.

Our data show that AHA is efficiently incorporated into viral proteins during CroV infection of $C$. burkhardae. Assuming similar AHA acquisition rates of viral and eukaryotic proteins, this suggests an efficient metabolic rewiring of the infected cell towards viral protein production. The resulting virocell (Forterre, 2012) thus differs drastically in its proteome from uninfected cells (Fig. 3A). BONCAT labeling with AHA exploits this hallmark property of viral infection by preferentially labeling viral proteins during a specific phase of infection and in combination with STED microscopy, we show that visualization of individual CroV particles is possible. Although BONCAT has been applied to viruses such adenovirus (Banerjee et al., 2011), vaccinia virus (Huang et al., 2017) and Emiliania huxleyi virus (EhV207) (Pasulka et al., 2018), we image individual giant virus particles for the first time using BONCAT in combination with super-resolution microscopy.

\section{AHA is incorporated in more than $95 \%$ of CroV particles}

Next, we analyzed the percentage of AHA-positive CroV particles that were produced during the infection of $C$. burkhardae in the continuous presence of AHA. After virus-induced lysis, we removed cell debris by filtration and collected CroV particles on a $0.02 \mu \mathrm{m}$ pore-size filter. AHA was labeled with Alexa Fluor 488 (AF488) alkyne dye by Click-iT ${ }^{\circledR}$ reaction and the DNA was stained with DAPI. The samples were analyzed by non-confocal fluorescent microscopy. The AHA-negative control only showed a signal in the DAPI channel (Fig. S4A), whereas the AHA-treated sample contained AF488 positive viruses and bacteria. We manually quantified the AF488 and DAPI signals of approximately 2,000 CroV-like particles derived from three independent infection assays and found that $95 \%-100 \%$ of DAPI-stained CroV-like particles were also positive for AHA-AF488 (Table S4 and Fig. S4B). This indicates that AHA incorporation during CroV infection is highly efficient and reproducible. We also found that some CroV-like particles were not packed with DNA, as they were positive for AF488 fluorescence but negative in the DAPI channel (Table S4). The percentage of empty CroV-like particles varied from $1 \%$ in two experiments to 
$19 \%$ in the other experiment. This may indicate that CroV packaging efficiency varies between different infection experiments, or could reflect variance during microscopy quantification.

The highly efficient AHA labeling of CroV particles (>95\%) is in concordance with results from other virus-host systems, for instance, an 87-94\% labeling efficiency was reported for EhV207 (Pasulka et al., 2018), >99\% for herpes simplex virus (Serwa et al., 2019) and 90\% for vaccinia virus (Huang et al., 2017). BONCAT can therefore be applied to a wide range of viruses.

\section{AHA incorporation does not affect CroV production or infectivity}

To assess if the presence of AHA altered CroV replication, we analyzed by quantitative PCR (qPCR) the number of $\mathrm{CroV}$ genome copies produced during three independent CroV infections in the presence and absence of AHA. Two of the three biological replicates showed a 2.8-fold decrease in CroV DNA copy number in the presence of AHA compared to the AHA-negative control, whereas in the third replicate the viral DNA levels increased 1.5-fold in the AHA-treated sample (Fig. S5). These differences are not statistically significant, as determined by Wilcoxon signed-rank test analysis ( $p$ value $=0.75$ ). Therefore, we conclude that an AHA concentration of $0.5 \mathrm{mM}$ during CroV infection does not significantly affect CroV replication.

A

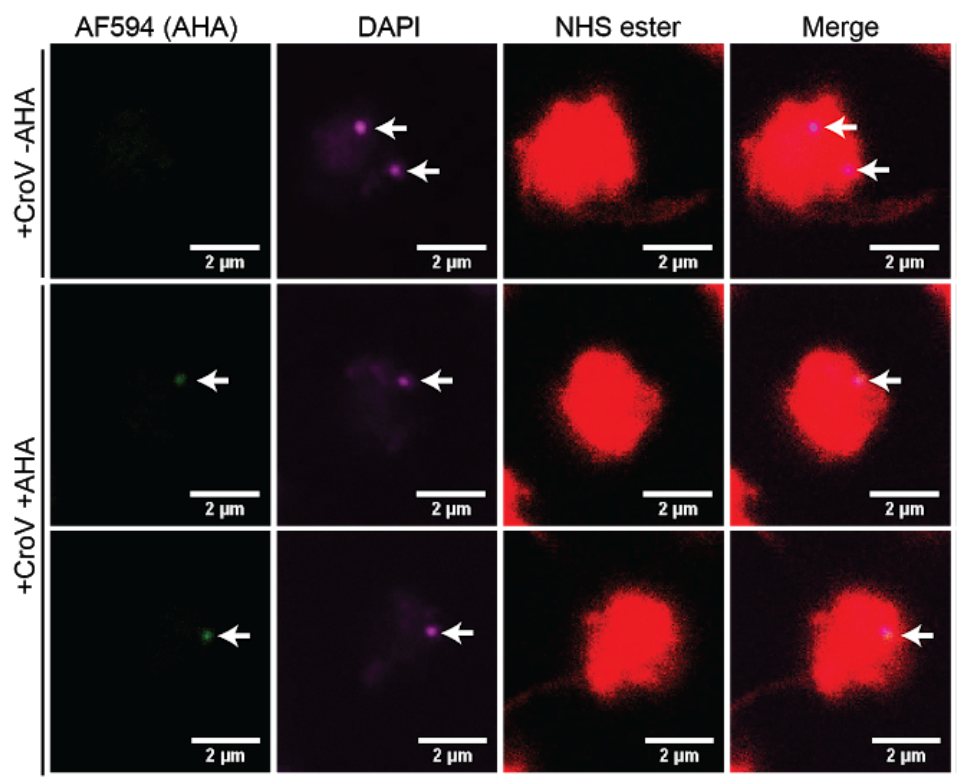

B

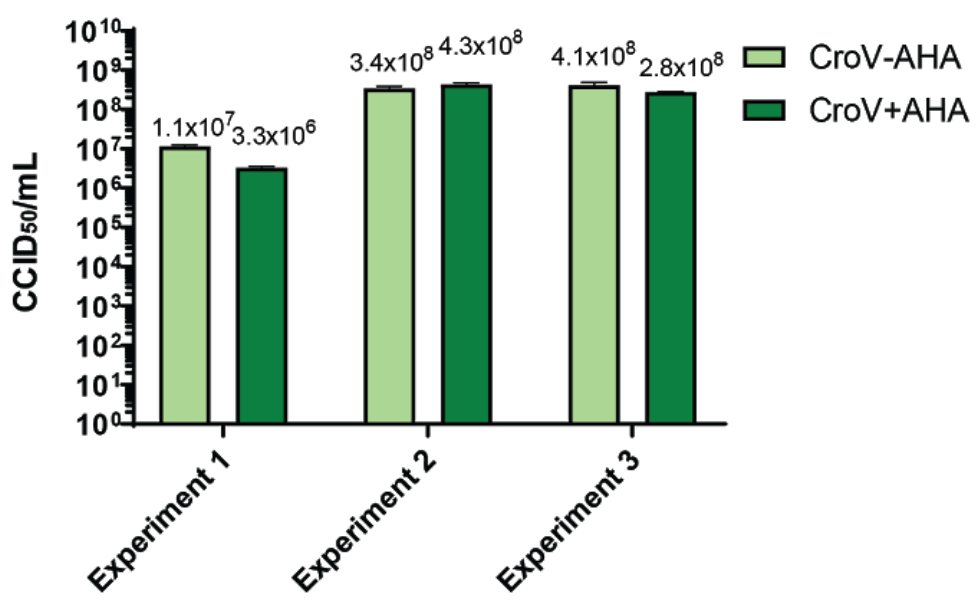

Figure 4. Infectivity assessment of AHA-labeled CroV particles. A) Confocal microscopy of early stages of CroV infection in $C$. burkhardae using AHA-labeled or unlabeled virions. $C$. burkhardae cultures were inoculated with native or AHA-labeled CroV particles at an MOI of 2 and incubated for five minutes prior to fixation. AHA residues were coupled to AF594, DNA was stained with DAPI, and flagellate cells were stained with AF488-NHS ester. Arrows point at AF594 and DAPI signals of virus-like particles. B) Infectivity comparison of native and AHA-labeled CroV particles. Infectivity values $\left(\mathrm{CCID}_{50} / \mathrm{mL}\right)$ of native (light green) or AHA-labeled (dark green) CroV particles derived from three independent infection experiments were determined by the end-point dilution method. Average values and SD (error bars) are shown for technical duplicates. 
To test whether AHA-labeling might impair CroV entry in $C$. burkhardae cells, cultures were incubated with AHA-positive or AHA-negative CroV particles for 5 minutes and then fixed. AHA was labeled with AF594 alkyne dye by Click-iT ${ }^{\circledR}$ reaction, DNA was stained with DAPI, and different lipid dyes for cytoplasmic membrane staining were tested, including Concanavalin A, CellBrite ${ }^{\mathrm{TM}}$ Fix and MemBrite ${ }^{\mathrm{TM}}$ Fix. Unfortunately, these dyes labeled inner membrane compartments of $C$. burkhardae both in live and fixed cells (data not shown). We therefore used an NHS ester linked to AF488 to label all proteins, allowing us to distinguish between extracellular and intracellular localization of CroV particles. As shown in Fig. 4A, infections with either native or AHA-containing CroV virions resulted in fluorescent signals of virus-like particles that were located inside $C$. burkhardae cells, indicating that the replacement of methionine by AHA does not affect CroV entry. Rapid fading of the AHA-linked AF594 signal in these samples, possibly caused by virion disassembly, prevented the use of high-resolution STED microscopy.

Finally, we compared the infectivity of AHA-labeled virions to native virions by end-point dilution assays using the same CroV lysates as for the qPCR test shown in Fig. S5. Based on genome copy quantification, the assay was started with same number of AHA-negative and AHA-positive CroV particles $\left(1.7 \times 10^{6}\right.$ for experiment $1,1.5 \times 10^{8}$ in experiment 2 and $2 \times 10^{8}$ in experiment 3 ). At three days post infection, we determined the infectious dose at which $50 \%$ of $C$. burkhardae cell cultures lysed $\left(C_{C} C D_{50}\right)$. The differences in $\mathrm{CCID}_{50}$ between AHA-negative and AHA-positive CroV particles were negligible in three independent assays (Fig. 4B), indicating that AHA has no apparent effect on CroV infectivity. This opens the possibility to study the CroV infection cycle with super-resolution microscopy using an antibody-free labeling method. In addition, this versatile, efficient, and non-toxic technique could be extended to the discovery and characterization of other giant viruses, even in environmental samples.

\section{Future perspectives}

Although AHA and its alkyne analog L-homopropargylglycine (HPG) have been mostly used in methionine auxotrophic organisms to increase the efficiency of incorporation (Wisse et al., 2017; Zhang et al., 2017; Saleh et al., 2019), its use has recently been extended to the analysis of natural bacterial communities, resulting in good incorporation in active methionine prototrophic bacteria (Hatzenpichler et al., 2014; Leizeaga et al., 2017; Couradeau et al., 2019). In addition, four wild-type prototrophic eukaryotic organisms were reported to incorporate AHA or HPG: Danio rerio (Hinz et al., 2012), Caenorhabditis elegans (Ullrich et al., 2014), Arabidiopsis thaliana (Glenn et al., 2017) and the coccolithophore Emiliania huxleyi (Pasulka et al., 2018).

In this study, we demonstrated efficient incorporation of the methionine analog AHA in cellular and viral proteins during infection of the marine heterotrophic protist $C$. burkhardae with the giant virus CroV. We show that metabolic labeling can be used to visualize individual CroV particles, especially when imaged with super-resolution microscopy. Moreover, incorporation of AHA does not affect viral infectivity (Fig. 5), enabling downstream in vivo experiments with labeled particles. BONCAT labeling with AHA can thus be applied to study the infection cycles of giant viruses in a methionine prototrophic background. 


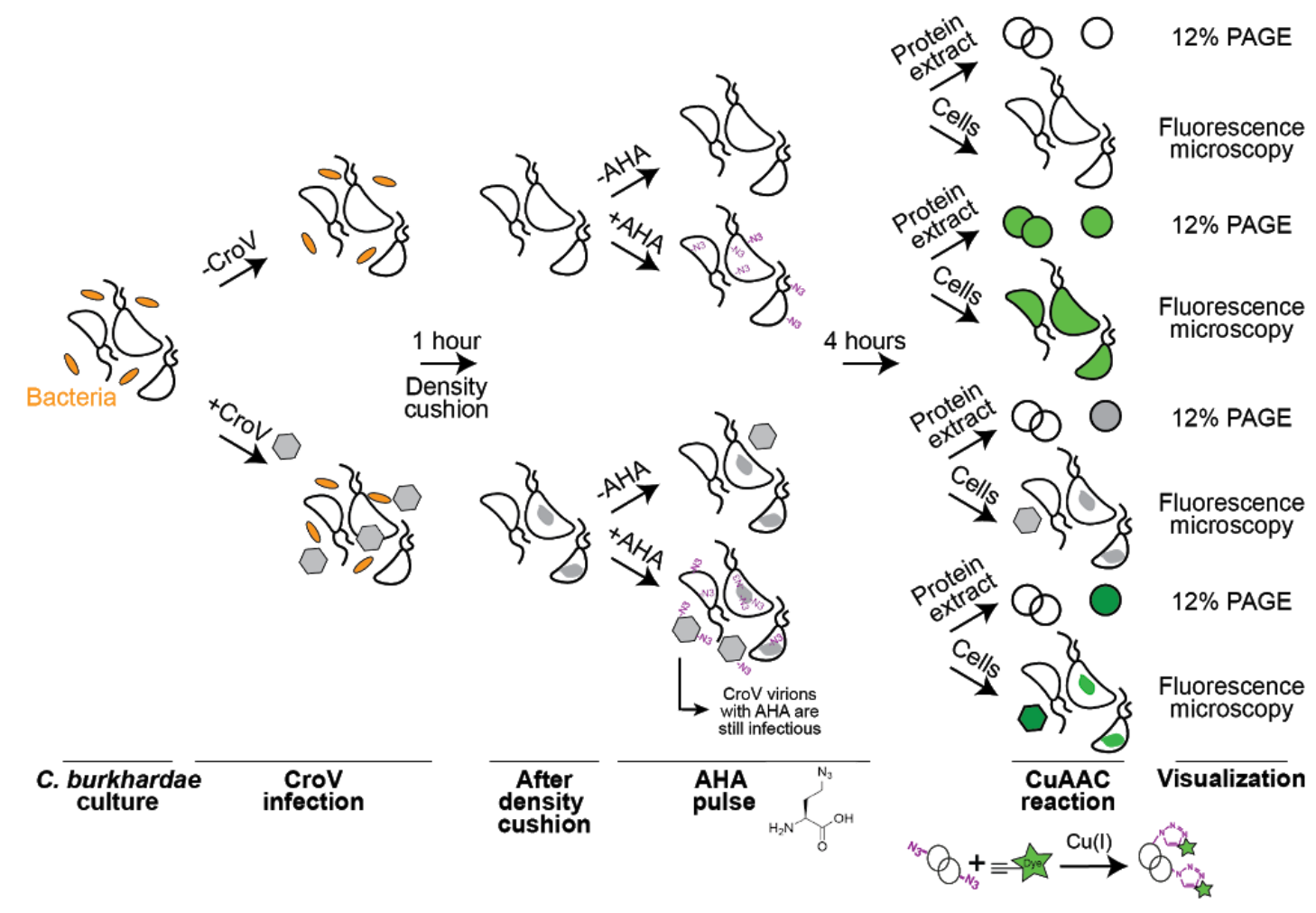

Figure 5. Experimental strategy for BONCAT labeling in C. burkhardae. Flagellate cultures were mock-infected or infected with CroV and incubated for one hour, followed by iodixanol density cushion centrifugation to remove bacteria and unattached CroV particles. Cells were then incubated for four hours with AHA or DMSO (negative control). AHA incorporation into nascent proteins was assessed by CuAAC (Click-IT)-mediated conjugation of AHA to fluorophores, either TAMRA alkyne dye for protein extracts and PAGE analysis, or AF594 or AF488 alkyne dyes for in situ cell analysis by fluorescence microscopy.

\section{Experimental procedures}

\section{Host and virus strains}

Cafeteria burkhardae (previously C. roenbergensis) RCC970-E3 strain was originally isolated from the South Pacific, approximately 2,200 km off the coast of Chile during the BIOSOPE cruise (Le Gall et al., 2008). Suspension cultures were maintained as described before (Fischer and Hackl, 2016). Cultures for experiments were grown in flat-bottom 3 L polycarbonate Erlenmeyer flasks (VWR, Germany) at 22-25 ${ }^{\circ} \mathrm{C}$. To determine the cell densities, $10 \mu \mathrm{L}$ of a $\mathrm{C}$. burkhardae culture were stained with $1 \mu \mathrm{L}$ of Lugol's acid iodine solution, loaded on a haemocytometer (Neubauer Chamber) and counted using a phase-contrast inverted microscope.

Cells were infected with CroV strain BV-PW1 (Garza and Suttle, 1995; Fischer et al., 2010). For virus stock production, $500 \mathrm{~mL}$ of $C$. burkhardae RCC970-E3 were infected at an initial cell density of $5 \times 10^{5}$ cells $/ \mathrm{mL}$ with an $\mathrm{MOI}$ of 0.1 . MOIs are based on $\mathrm{CCID}_{50} / \mathrm{mL}$ values calculated by the end-point dilution method 
described below. Cultures were incubated for 4 days until cells had lysed. Finally, cell debris was removed using a $1.2 \mu \mathrm{m}$ filter.

\section{lodixanol density cushion centrifugation}

All centrifugation and incubation steps in this study were carried out at $20^{\circ} \mathrm{C}$ unless specified otherwise. C. burkhardae RCC970-E3 cultures were centrifuged for $5 \mathrm{~min}$ at 4,500 g. Pellets were resuspended at a density of $2.5 \times 10^{8}$ cells $/ \mathrm{mL}$ in $1 \times$ PBS with $0.5 \mathrm{M} \mathrm{NaCl}$. A total of $2.5 \times 10^{8}$ cells were loaded in a SW40 ultra-clean centrifuge tubes (Beckman, Germany) containing $10 \%$ and $20 \%$ iodixanol density cushions (OptiPrep $^{\mathrm{TM}}$, Sigma-Aldrich, Germany) cushion diluted in $1 \mathrm{x}$ PBS with $0.5 \mathrm{M} \mathrm{NaCl}$, as described by (Duponchel et al., 2019). Tubes were centrifuged for $20 \mathrm{~min}$ in a SW40Ti rotor at 20,000 rpm with slow braking in a Beckman Coulter Optima XE-90 ultracentrifuge. The interphase band containing $C$. burkhardae cells was recovered and washed with $f / 2$ medium to remove residual iodixanol. After centrifugation for $5 \mathrm{~min}$ at 4,500 g, samples were resuspended in $\mathrm{f} / 2$ medium to a final concentration of $1 \times 10^{7}$ cells $/ \mathrm{mL}$. Next, $5 \times 10^{6}$ cells from treated and untreated conditions were centrifuged for $5 \mathrm{~min}$ at 4,500 $\mathrm{g}$ and the pellets were resuspended in 4\% paraformaldehyde (PFA, Merck, Germany), and incubated for $20 \mathrm{~min}$. After a $5 \mathrm{~min}$ centrifugation step at 7,000 g, pellets were washed with 1x PBS and centrifuged again. Pellets were resuspended in permeabilization buffer ( $3 \%(w / v)$ bovine serum albumin (BSA, Sigma-Aldrich, Germany) with 0.5\% (v/v) Triton X-100 (Sigma-Aldrich, Germany) in 1x PBS) and incubated for $15 \mathrm{~min}$. Cells were then immobilized by centrifuging for $5 \mathrm{~min}$ at 2,250 g onto poly-L-lysine (PLL)-treated coverslips, washed with $1 \times$ PBS and mounted on glass slides using ProLong ${ }^{\mathrm{TM}}$ Diamond Antifade Mountant with DAPI (ThermoFisher, Germany). To obtain the PLL-treated coverslips, 15 $\mathrm{mm}$-diameter coverslips were washed sequentially with $70 \%$ ethanol and $\mathrm{H}_{2} \mathrm{O}$ and treated with $0.01 \%$ (v/v) PLL solution (Sigma-Aldrich, Germany) for 20 min and drying overnight.

\section{Fluorescence microscopy}

Imaging of bacterial backgrounds and quantification of CroV-AHA particles was performed on a Zeiss Axiovert 22M microscope with phase contrast and DAPI HC BP and GFP (for AF488) HC filter sets (F36-513 and F36-525 respectively, AHF Analysentechnik AG). For confocal and super-resolution microscopy, we used an Abberior easy 3D STED/RESOLFT QUAD scanning microscope (Abberior Instruments $\mathrm{GmbH}$, Göttingen, Germany) built on a motorized inverted microscope IX83 (Olympus, Tokyo, Japan). The microscope was equipped with pulsed STED lasers at $595 \mathrm{~nm}$ and $775 \mathrm{~nm}$, and with $355 \mathrm{~nm}, 405 \mathrm{~nm}, 485 \mathrm{~nm}, 561 \mathrm{~nm}$, and $640 \mathrm{~nm}$ excitation lasers. Spectral detection was performed with avalanche photodiodes (APD) in the following spectral windows: $600-700 \mathrm{~nm}$ for AF594, 420-475 $\mathrm{nm}$ for DAPI, and 505-530 nm for AF488. Images were acquired with a 100x/1.40 UPlanSApo Oil immersion objective lens (Olympus). Pixel size was $200 \mathrm{~nm}$ for all overview pictures, $100 \mathrm{~nm}$ for close-up images in Fig. 2B, and $25 \mathrm{~nm}$ for images in Figs. 3B and 4A. For super-resolution imaging of AF594, the STED line at $775 \mathrm{~nm}$ was used. Image acquisition parameters were kept constant across the different samples to enable the quantification of signal intensities.

Microscopy images were processed and visualized with the ImSpector software package (Max-Planck Innovation) and/or ImageJ (imagej.nih.gov/ij/). Brightness and contrast settings were applied evenly to all images of an experiment. 


\section{Flow cytometry}

Seven independent cultures were analyzed, which were split into density cushion-purified or untreated batches with at least $10^{7} \mathrm{C}$. burkhardae cells each. The untreated batch was centrifuged for $10 \mathrm{~min}$ at 4,500 $\mathrm{g}$ and washed once in $1 \times$ PBS. After a second centrifugation step, the pellet was fixed with $4 \%$ PFA as described above. After a 5 min centrifugation at 7,000 g, cells were resuspended in $500 \mu \mathrm{l}$ of $1 \mathrm{x}$ PBS and stored at $4{ }^{\circ} \mathrm{C}$. The treated batch was centrifuged $10 \mathrm{~min}$ at 4,500 $\mathrm{g}$ and the pellet was subjected to iodixanol density cushion centrifugation as described above. The recovered cells were centrifuged for 10 $\mathrm{min}$ at 4,500 $\mathrm{g}$ and the pellet was incubated for $20 \mathrm{~min}$ at RT in 4\% PFA. After centrifugation at 7,000 $\mathrm{g}$ for $5 \mathrm{~min}$, treated samples were resuspended in $500 \mu \mathrm{l}$ of $1 \mathrm{x}$ PBS and stored at $4{ }^{\circ} \mathrm{C}$.

Cell count data were acquired on an LSR Fortessa X-20 cytometer (BD, Germany) and displayed in dot plots of SSC-A versus FSC-A on logarithmic axes (ranging from $10^{-3}$ to $10^{5}$ ). The FSC-A threshold was set to its minimum (200 r.u.) and a medium flow rate (approx. $35 \mu \mathrm{l} / \mathrm{min}$ ) was used during acquisition. The sample injection port was cleaned between samples to prevent cross-contamination. Samples were filtered on cell-strainer cap (Falcon ${ }^{\circledR}$, VWR, Germany), diluted 1:2 with 1x PBS and vortexed before acquisition. After stabilization of the flow rate, 10,000 total events per sample were acquired in technical duplicates.

Analysis of the raw data files was performed using FlowJo 10.5.3 software (BD, Germany). C. burkhardae cells, bacterial cells and background events were gated and the number of events for each cell population was obtained. The percentage of bacterial and flagellate cells corresponded to the average cell count in each treated sample divided by the average count of the respective untreated sample.

\section{Methionine synthesis genes in C. burkhardae}

We used methionine synthesis proteins previously identified in the diatom Thalassiosira pseudonana (Bromke and Hesse, 2015) to identify candidate genes in C. burkhardae using BLAST 2.9.0+ (Altschul et al., 1990). We then annotated those candidate genes against the EggNOG v4.5.1 (Huerta-Cepas et al., 2016) database to confirm their putative functions (Table S1).

For extraction of total RNA from C. burkhardae RCC970-E3 culture, $500 \mu \mathrm{l}$ of an exponentially growing suspension culture, which was previously submitted to iodixanol density cushion, were centrifuged for $5 \mathrm{~min}$ at $4,500 \mathrm{~g}, 4{ }^{\circ} \mathrm{C}$. The supernatants were discarded and the cell pellets were immediately flash-frozen in $\mathrm{N}_{2}(\mathrm{I})$ and stored at $-80{ }^{\circ} \mathrm{C}$ until further use. RNA extraction was performed with the Qiagen RNeasy Mini Kit (Qiagen, Hilden, Germany) following the protocol for purification of total RNA from animal cells using spin technology. Cells were disrupted with QIAshredder homogenizer spin columns (Qiagen, Hilden, Germany) and an on-column DNase I digest was performed with the Qiagen RNase-Free DNase Set (Qiagen, Hilden, Germany). RNA was eluted in $50 \mu$ l of RNase-free molecular biology grade water and DNA was removed by incubation with $1 \mu$ I TURBO DNase $(2 \mathrm{U} / \mu \mathrm{l})$ for $30 \mathrm{~min}$ at $37{ }^{\circ} \mathrm{C}$ according to the manufacturer's instructions (Ambion via ThermoFisher Scientific, Germany). RNA samples were analyzed for quantity and integrity with a Qubit 4 Fluorometer (Invitrogen via ThermoFisher Scientific, Germany) using the RNA Broad Range and RNA Integrity and Quality kits, respectively. 
For cDNA synthesis, $6 \mu$ of each RNA sample were reverse transcribed using the Qiagen QuantiTect Reverse Transcription Kit according to the manufacturer's instructions (Qiagen, Hilden, Germany). This protocol included an additional DNase treatment step and the reverse transcription reaction used a mix of random hexamers and oligo(dT) primers. Control reactions to test for gDNA contamination were performed for all samples by adding double-distilled (dd) $\mathrm{H}_{2} \mathrm{O}$ instead of reverse transcriptase to the reaction mix. The cDNA was diluted fivefold with RNase-free $\mathrm{H}_{2} \mathrm{O}$ and analyzed by PCR with gene-specific primers (Table S5).

PCR amplification was performed using $2 \mu \mathrm{l}$ of the diluted cDNA in a $25 \mu \mathrm{l}$ reaction mix containing 0.02 $U$ of $\mathrm{Q}^{\circledR}{ }^{\circledR}$ High-Fidelity DNA Polymerase (NEB, Germany), $200 \mu \mathrm{M}$ of dNTP, $5 \mu \mathrm{l}$ of $5 \mathrm{x}$ Q5 High GC Enhancer and $0.5 \mu \mathrm{M}$ of each primer in $1 \mathrm{x}$ of the Q5 Reaction Buffer. The PCRs were performed in a ProFlex PCR System (Applied Biosystems via ThermoFisher Scientific, Germany) with the following cycling conditions: $30 \mathrm{~s}$ denaturation at $98{ }^{\circ} \mathrm{C}, 35$ cycles of $10 \mathrm{~s}$ denaturation at $98{ }^{\circ} \mathrm{C}, 20 \mathrm{~s}$ annealing at the temperature given by NEB TM calculator (https://tmcalculator.neb.com), and $25 \mathrm{~s}$ extension at $72{ }^{\circ} \mathrm{C}$. The cycles were followed by a final extension period of $2 \mathrm{~min}$ at $72{ }^{\circ} \mathrm{C}$. For product analysis, $1 \mu \mathrm{l}$ of each reaction was loaded on a $1 \%(\mathrm{w} / \mathrm{v})$ agarose gel supplemented with GelRed. The marker lanes contained $0.5 \mu \mathrm{g}$ of GeneRuler $1 \mathrm{~kb}$ DNA ladder (Fermentas, ThermoFisher Scientific, Germany). The gel was run for $1 \mathrm{~h}$ at $100 \mathrm{~V}$ and visualized on a ChemiDoc MP Imaging System (BioRad, Germany).

\section{AHA labeling of $C$. burkhardae and CroV}

To study AHA incorporation in newly synthesized C. burkhardae proteins, different AHA concentrations were tested. First, $2.5 \times 10^{8}$ cells were purified by iodixanol density cushion centrifugation as described above. Recovered cells were resuspended in $\mathrm{f} / 2$ medium (without yeast extract) at a density of $10^{7}$ cells $/ \mathrm{mL}$. For each sample, $1.5 \times 10^{7}$ cells were incubated for 4 hours with $3 \mu \mathrm{L}$ of AHA diluted in DMSO (Acros Organics via ThermoFisher Scientific, Germany) to final concentrations of $0,0.25,0.5,1$ or $2 \mathrm{mM}$ AHA. After incubation, samples were prepared for SDS-PAGE and microscopy analysis as described below.

To analyze AHA incorporation in CroV proteins, $1 \mathrm{~L}$ of $C$. burkhardae RCC970-E3 suspension culture was diluted to $4 \times 10^{5}$ cells $/ \mathrm{mL}$ on the day before the experiment. A total of $2.5 \times 10^{8}$ cells were then infected with $\mathrm{CroV}$ at an $\mathrm{MOI}$ of 2 (stock quantified by end-point dilution). The mock infection received $\mathrm{f} / 2$ medium instead of CroV. After a 1 hour incubation, bacteria and free CroV particles were removed by density cushion centrifugation. Recovered cells were resuspended in $\mathrm{f} / 2$ medium at a density of $1 \times 10^{7}$ cells $/ \mathrm{mL}$ and incubated for a total infection time of 7 or 11 hours. At 3 and 7 hours post infection, $0.5 \mu \mathrm{L}$

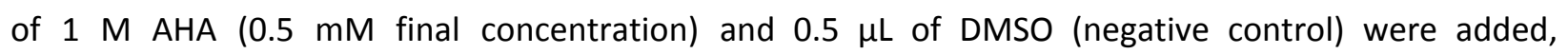
respectively, resulting in a 4 hour incubation time prior to harvesting.

AHA incorporation was assessed by SDS-PAGE using $6 \times 10^{6}$ cells. Cells were centrifuged for 6 min at 5,000 $\mathrm{g}$ after AHA incubation. Pellets were washed with $500 \mu \mathrm{L}$ of $1 \mathrm{x}$ PBS and centrifuged again. Samples were frozen at $-80^{\circ} \mathrm{C}$ until use. To extract $C$. burkhardae and $\mathrm{CroV}$ proteins, pellets were resuspended in $50 \mu \mathrm{L}$ of lysis buffer (20 mM Tris- $\mathrm{HCl}$ pH 7.5, $1 \mathrm{mM}$ EDTA, $0.5 \mathrm{mM} \mathrm{Na}_{3} \mathrm{VO}_{4}, 1 \mathrm{mM}$ benzamidine hydrochloride (Sigma-Aldrich, Germany), 5x cOmplete ${ }^{\mathrm{TM}}$ EDTA-free protease inhibitor cocktail (Roche, Germany), 10\% $(\mathrm{v} / \mathrm{v})$ glycerol, $1 \%(\mathrm{v} / \mathrm{v})$ Igepal $^{\circledR}$ (Sigma-Aldrich, Germany) and $100 \mu \mathrm{M}$ phenylmethylsulfonyl fluoride (Sigma-Aldrich, Germany) in $\mathrm{H}_{2} \mathrm{O}$ ) and incubated $20 \mathrm{~min}$ on ice. Lysis was checked by phase-contrast 
inverted microscopy and by comparing the SDS-PAGE banding pattern of $5 \mu \mathrm{L}$ of the lysate (total protein fraction) and $5 \mu \mathrm{L}$ of the lysate after centrifuging for $15 \mathrm{~min}$ at $12,000 \mathrm{~g}, 4^{\circ} \mathrm{C}$ (soluble protein fraction). After cell lysis, incorporated AHA was detected by labeling $40 \mu \mathrm{L}$ of each soluble protein fraction with $22.5 \mu \mathrm{M}$ of TAMRA alkyne in a final volume of $128 \mu \mathrm{L}$ following the Click-IT ${ }^{\circledR}$ Protein Reaction Buffer Kit recommendations (ThermoFisher, Germany). After methanol/chloroform protein precipitation, protein pellets were resuspended in $20 \mu \mathrm{L}$ of $1 \mathrm{x}$ Laemmli buffer (10 min shaking followed by 10 min incubation at $70{ }^{\circ} \mathrm{C}$ ) and $2 \mu \mathrm{L}$ were loaded on a $12 \%$ SDS-PA gel. After electrophoresis at $150 \mathrm{~V}$ for 1.5 hours, gels were stained with InstantBlue ${ }^{\circledR}$ Coomassie (Expedeon via Abcam, Germany) and visualized on a ChemiDoc MP Imaging System using rhodamine settings for TAMRA detection and Coomassie settings for Coomassie detection.

For microscopy, $3 \times 10^{6}$ cells were centrifuged for $6 \mathrm{~min}$ at 5,000 $\mathrm{g}$ and fixed and permeabilized as described above. After pelleting the cells for $5 \mathrm{~min}$ at 7,000 g, AHA was labelled with $0.5 \mu \mathrm{M}$ AF594 alkyne dye following the Click-i $\mathrm{T}^{\circledR}$ Cell Reaction Buffer Kit instructions. Cells were centrifuged for 5 min at 7,000 g and washed twice with $200 \mu \mathrm{L}$ of $1 x$ PBS containing 3\% BSA and $0.1 \%$ (v/v) Tween-20 (BioRad, Germany). Mounting of cells for STED microscopy was performed as described above.

\section{Production and analysis of AHA-labeled CroV}

Three independent batches of AHA-containing and AHA-free CroV particles were produced and further analyzed by fluorescence microscopy, qPCR and infectivity assays. For each batch, $2 \times 10^{7}$ CroV-infected $C$. burkhardae cells at a density of $1 \times 10^{7}$ cells $/ \mathrm{mL}$ were density cushion-purified and incubated for 24 hours with $1 \mu \mathrm{L}$ of $1 \mathrm{M} \mathrm{AHA}(0.5 \mathrm{mM}$ final concentration) or $1 \mu \mathrm{L}$ of DMSO for the negative control. After cell lysis, samples were $1.2 \mu \mathrm{m}$ filtered and $100 \mu \mathrm{L}$ of the filtrate were fixed with $32.5 \mu \mathrm{L}$ of 16\% PFA (4\% final) for $20 \mathrm{~min}$. Samples were immobilized on a $25 \mathrm{~mm}$ Anodisc Whatman filter with $0.02 \mu \mathrm{m}$ pore size, as described previously (Berjón-Otero et al., 2019) and permeabilized for $15 \mathrm{~min}$. AHA residues were coupled to $0.5 \mu \mathrm{M}$ AF488 alkyne dye using the Click-iT ${ }^{\circledR}$ Cell Reaction Buffer Kit. Filters were washed three times with $1 \mathrm{~mL}$ of 3\% BSA with $0.1 \%$ Tween-20 in 1x PBS and mounted on slides as described above. CroV particles positive for DAPI and AF488 were manually counted using ImageJ software.

For the CroV cell entry assay, $5 \times 10^{6}$ density cushion-purified $C$. burkhardae cells were resuspended with AHA-containing or AHA-free CroV particles at MOI 2 (based on qPCR). After 5 min of incubation, cells were fixed, permeabilized, and immobilized as described before. AHA was labeled with $0.5 \mu \mathrm{M}$ AF594 alkyne dye using the Click-iT ${ }^{\circledast}$ Cell Reaction Buffer Kit. Coverslips were washed three times with $200 \mu \mathrm{L}$ of 3\% BSA with $0.1 \%$ Tween-20 in 1x PBS and once with 1x PBS. C. burkhardae cells were stained 2 min at RT with $40 \mu \mathrm{g} / \mathrm{mL}$ AF488 NHS ester (ThermoFisher, Germany). Prior to mounting and STED microscopy, coverslips were washed three times with 1x PBS.

\section{Quantitative PCR}

Viral genomic DNA (gDNA) was extracted from $100 \mu$ l of viral suspension complemented with $100 \mu$ of 1x PBS with the QIAamp DNA Mini kit (Qiagen, Hilden, Germany) following the manufacturer's instructions for DNA purification of total DNA from cultured cells, with a single elution step in $100 \mu$ of $\mathrm{ddH}_{2} \mathrm{O}$ and storage at $-20{ }^{\circ} \mathrm{C}$. 
$1 \mu \mathrm{l}$ of gDNA was used as template in a $20 \mu \mathrm{l}$ qPCR reaction containing $10 \mu \mathrm{l}$ of $2 x$ Fast-Plus EvaGreen Master Mix with low ROX dye (Biotium, Inc. via VWR, Germany), 10 pmol of each forward and reverse primer (Table 1), and $8.8 \mu \mathrm{l}$ of $\mathrm{dd}_{2} \mathrm{O}$. No-template controls (NTC) contained $\mathrm{ddH}_{2} \mathrm{O}$ instead of gDNA. Each qPCR reaction (sample, NTC, or standard) was performed in technical duplicates, with individual replicates differing in their quantification cycles $(\mathrm{Cq})$ by about $0.08 \%$ on average $(0.084 \% \pm 0.086 \%$, $\mathrm{n}=6$ ). The limit of detection for this assay was $\approx 10$ copies, which equates to about $5,000 \mathrm{copies} / \mathrm{mL}$ of suspension culture. The $\mathrm{Cq}$ values of the NTC controls were consistently below the limit of detection. Thermal cycling was performed in a Stratagene Mx3005P qPCR system (Agilent Technologies, Germany) with the following settings: $95{ }^{\circ} \mathrm{C}$ for $5 \mathrm{~min}, 40$ cycles of $95{ }^{\circ} \mathrm{C}$ for $10 \mathrm{~s}$ followed by $60{ }^{\circ} \mathrm{C}$ for $25 \mathrm{~s}$ and $72{ }^{\circ} \mathrm{C}$ for $25 \mathrm{~s}$, a single cycle of $72{ }^{\circ} \mathrm{C}$ for $5 \mathrm{~min}$, and a final dissociation curve was recorded from $50{ }^{\circ} \mathrm{C}$ to $95{ }^{\circ} \mathrm{C}$. qPCR results were analyzed using MxPro qPCR software version 4.10 (Stratagene via Agilent Technologies, Germany). The threshold fluorescence was set using the amplification-based option of MxPro software. Standard curves were calculated from a tenfold dilution series that ranged from $10^{1}$ to $10^{8}$ molecules of gDNA extracted from a known amount of CroV particles, the concentration of which had been determined by epifluorescence microscopy. The target sequence crov283 gene (GenBank accession number ADO67316.1) was amplified by primers CroV-qPCR-9 and CroV-qPCR-10 (Table S5). Using these primers, the R2 value for the standard curve was 0.982 , the amplification efficiency was $115.0 \%$, and the standard curve equation was $y=-2.995 \log (x)+40.91$.

\section{CroV infectivity assays}

End-point dilution assays for measuring infective titers of CroV have been described previously (Fischer and Hackl, 2016). Plates were inspected for cell lysis at 5 days post infection by phase-contrast microscopy. For the infectivity comparison of AHA-labeled versus AHA-free CroV virions, dilutions ranged from $10^{-3}$ to $10^{-9}$ and plates were analyzed at 3 days post infection. The statistical method by Reed and Muench (Reed and Muench, 1938) was used to determine the $\mathrm{CCID}_{50} / \mathrm{mL}$.

\section{Mass spectrometry}

To identify SDS-PAGE protein bands, peptide map fingerprinting (PMF) was performed using standard procedures, including protein treatment with dithiothreitol and iodoacetamide followed by trypsin digestion as described by Wulfmeyer (Wulfmeyer et al., 2012). Briefly, peptides eluted from gel slices were purified on ZipTip C18 columns (Millipore, Germany) and applied to a stainless steel target together with $\alpha$-cyano-4-hydroxycinnamic acid as a matrix. The peptides were analyzed in reflectron mode using a Shimadzu Biotech Axima Performance MALDI-TOF mass spectrometer. Calibration was via nearest neighbor external standards, using 8 peptides (Sigma Aldrich) with $\mathrm{m} / \mathrm{z}$ ratios from 757.4 to 3657.9. Mass lists from the individual PMF spectra were submitted to an in-house Mascot Server PMF search engine using the $\mathrm{NCBI} \mathrm{nr}$ database, limiting the taxonomic range to $C$. burkhardae and CroV. Additional search parameters were set to monoisotopic mass, charge $1+$, maximum of 1 missed cleavage, peptide tolerance of $0.3 \mathrm{~m} / \mathrm{z}$, and $p<0.05$. The root mean square (RMS) errors on the peptide mass matches ranged from 21-102 ppm. As a control, all searches were repeated using the decoy database generated by the Mascot Server software, using the same settings. 


\section{Acknowledgments}

This work was supported by the Max Planck Society, the Gordon \& Betty Moore Foundation (grant \#5734), and a European Molecular Biology Organization (EMBO) long-term fellowship to M.B.-O. (ALTF-726-2017). We are grateful to C. Suttle for access to host and virus strains, and to the Roscoff team for maintaining and distributing protist strains. We thank A. Weinmann for technical assistance, E. D'Este for support with confocal and STED microscopy, S. Fabritz, M. Müller and C. Ulrich for mass spectrometry, C. Roome for IT support and I. Schlichting for mentoring and support.

The authors declare no conflict of interest.

\section{References}

Altschul, S.F., Gish, W., Miller, W., Myers, E.W., and Lipman, D.J. (1990) Basic local alignment search tool. J Mol Biol 215: 403-410.

Atkins, M.S., Teske, A.P., and Anderson, O.R. (2000) A survey of flagellate diversity at four deep-sea hydrothermal vents in the Eastern Pacific Ocean using structural and molecular approaches. $J$ Eukaryot Microbiol 47: 400-411.

Banerjee, P.S., Ostapchuk, P., Hearing, P., and Carrico, I.S. (2011) Unnatural amino acid incorporation onto Adenoviral (Ad) coat proteins facilitates chemoselective modification and retargeting of $\mathrm{Ad}$ Type 5 vectors. J Virol 85: 7546-7554.

Bartlem, D., Lambein, I., Okamoto, T., Itaya, A., Uda, Y., Kijima, F., et al. (2000) Mutation in the threonine synthase gene results in an over-accumulation of soluble methionine in Arabidopsis. Plant Physiol 123: 101-110.

Berjón-Otero, M., Duponchel, S., and Fischer, M.G. (2019) Fluorescence microscopy with the marine heterotrophic flagellate Cafeteria roenbergensis. protocols.io DOI: 10.17504/protocols.io.qjmduk6.

Berjón-Otero, M., Koslová, A., and Fischer, M.G. (2019) The dual lifestyle of genome-integrating virophages in protists. Ann N Y Acad Sci 1447: 97-109.

Boenigk, J. and Arndt, H. (2002) Bacterivory by heterotrophic flagellates: Community structure and feeding strategies. Antonie van Leeuwenhoek, Int J Gen Mol Microbiol 81: 465-480.

Boenigk, J. and Arndt, H. (2000) Particle handling during interception feeding by four species of heterotrophic nanoflagellates. J Eukaryot Microbiol 47: 350-358.

Born, T.L. and Blanchard, J.S. (1999) Enzyme-catalyzed acylation of homoserine: mechanistic characterization of the Escherichia coli metA -encoded homoserine transsuccinylase. Biochemistry 38: $14416-14423$.

Bromke, M.A. and Hesse, H. (2015) Phylogenetic analysis of methionine synthesis genes from 
Thalassiosira pseudonana. Springerplus 4: 391.

De Corte, D., Paredes, G., Yokokawa, T., Sintes, E., and Herndl, G.J. (2019) Differential response of Cafeteria roenbergensis to different bacterial and archaeal prey characteristics. Microb Ecol 78: $1-5$.

Couradeau, E., Sasse, J., Goudeau, D., Nath, N., Hazen, T.C., Bowen, B.P., et al. (2019) Probing the active fraction of soil microbiomes using BONCAT-FACS. Nat Commun 10: 2770.

Dieterich, D.C., Lee, J.J., Link, A.J., Graumann, J., Tirrell, D.A., and Schuman, E.M. (2007) Labeling, detection and identification of newly synthesized proteomes with bioorthogonal non-canonical amino-acid tagging. Nat Protoc 2: 532-540.

Dieterich, D.C., Link, A.J., Graumann, J., Tirrell, D.A., and Schuman, E.M. (2006) Selective identification of newly synthesized proteins in mammalian cells using bioorthogonal noncanonical amino acid tagging (BONCAT). Proc Natl Acad Sci 103: 9482-9487.

Duponchel, S., Berjón-Otero, M., and Fischer, M.G. (2019) Density-based removal of bacteria from a culture of the marine heterotrophic flagellate Cafeteria roenbergensis. protocols.io DOI: 10.17504/protocols.io.qiiduce.

Duponchel, S. and Fischer, M.G. (2019) Viva lavidaviruses! Five features of virophages that parasitize giant DNA viruses. PLoS Pathog 15: e1007592.

Fenchel, T. and Patterson, D.J. (1988) Cafeteria roenbergensis nov. gen., nov. sp., a heterotrophic microflagellate from marine plankton. Mar Microb Food Webs 3: 9-19.

Ferla, M.P. and Patrick, W.M. (2014) Bacterial methionine biosynthesis. Microbiology 160: 1571-1584.

Finkelstein, J.D. (1990) Methionine metabolism in mammals. J Nutr Biochem 1: 228-237.

Fischer, M.G., Allen, M.J., Wilson, W.H., and Suttle, C.A. (2010) Giant virus with a remarkable complement of genes infects marine zooplankton. Proc Natl Acad Sci U S A 107: 19508-19513.

Fischer, M.G. and Hackl, T. (2016) Host genome integration and giant virus-induced reactivation of the virophage mavirus. Nature 540: 288-291.

Fischer, M.G., Kelly, I., Foster, L.J., and Suttle, C.A. (2014) The virion of Cafeteria roenbergensis virus (CroV) contains a complex suite of proteins for transcription and DNA repair. Virology 466-467: 82-94.

Fischer, M.G. and Suttle, C.A. (2011) A virophage at the origin of large DNA transposons. Science (80-) 332: 231-234.

Forterre, P. (2012) Virocell Concept, The. eLS DOI: 10.1002/9780470015902.a002326.

Le Gall, F., Rigaut-Jalabert, F., Marie, D., Garczarek, L., Viprey, M., Gobet, A., and Vaulot, D. (2008) Picoplankton diversity in the South-East Pacific Ocean from cultures. Biogeosciences 5: 203-214.

Garza, D.R. and Suttle, C.A. (1995) Large double-stranded DNA viruses which cause the lysis of a marine 
heterotrophic nanoflagellate (Bodo sp) occur in natural marine viral communities. Aquat Microb Ecol 9: 203-210.

Glenn, W.S., Stone, S.E., Ho, S.H., Sweredoski, M.J., Moradian, A., Hess, S., et al. (2017) Bioorthogonal Noncanonical Amino Acid Tagging (BONCAT) enables time-resolved analysis of protein synthesis in native plant tissue. Plant Physiol 173: 1543-1553.

Goudarzi, M. and Born, T.L. (2006) Purification and characterization of Thermotoga maritima homoserine transsuccinylase indicates it is a transacetylase. Extremophiles 10: 469-478.

Hackl, T., Martin, R., Barenhoff, K., Duponchel, S., Heider, D., and Fischer, M.G. (2020) Four high-quality draft genome assemblies of the marine heterotrophic nanoflagellate Cafeteria roenbergensis. Sci Data 7: 29.

Hatzenpichler, R., Scheller, S., Tavormina, P.L., Babin, B.M., Tirrell, D.A., and Orphan, V.J. (2014) In situ visualization of newly synthesized proteins in environmental microbes using amino acid tagging and click chemistry. Environ Microbiol 16: 2568-2590.

Helliwell, K.E., Wheeler, G.L., Leptos, K.C., Goldstein, R.E., and Smith, A.G. (2011) Insights into the evolution of vitamin B12 auxotrophy from sequenced algal genomes. Mol Biol Evol 28: 2921-2933.

Hinz, F.I., Dieterich, D.C., Tirrell, D.A., and Schuman, E.M. (2012) Noncanonical amino acid labeling in vivo to visualize and affinity purify newly synthesized proteins in larval Zebrafish. ACS Chem Neurosci 3: 40-49.

Huang, L.-L., Liu, K., Zhang, Q., Xu, J., Zhao, D., Zhu, H., and Xie, H.-Y. (2017) Integrating two efficient and specific bioorthogonal ligation reactions with natural metabolic incorporation in one cell for virus dual labeling. Anal Chem 89: 11620-11627.

Huerta-Cepas, J., Szklarczyk, D., Forslund, K., Cook, H., Heller, D., Walter, M.C., et al. (2016) eggNOG 4.5: a hierarchical orthology framework with improved functional annotations for eukaryotic, prokaryotic and viral sequences. Nucleic Acids Res 44: 286-293.

Kiick, K.L., Saxon, E., Tirrell, D.A., and Bertozzi, C.R. (2002) Incorporation of azides into recombinant proteins for chemoselective modification by the Staudinger ligation. Proc Natl Acad Sci 99: 19-24.

Krupovic, M., Kuhn, J.H., and Fischer, M.G. (2016) A classification system for virophages and satellite viruses. Arch Virol 161: 233-47.

Leizeaga, A., Estrany, M., Forn, I., and Sebastián, M. (2017) Using click-chemistry for visualizing in situ changes of translational activity in planktonic marine bacteria. Front Microbio/ 8: 2360.

Massana, R., del Campo, J., Dinter, C., and Sommaruga, R. (2007) Crash of a population of the marine heterotrophic flagellate Cafeteria roenbergensis by viral infection. Environ Microbiol 9: 2660-2669.

Mutsafi, Y., Zauberman, N., Sabanay, I., and Minsky, A. (2010) Vaccinia-like cytoplasmic replication of the giant Mimivirus. Proc Natl Acad Sci U S A 107: 5978-5982.

O’Kelly, C.J. and Patterson, D.J. (1996) The flagellar apparatus of Cafeteria roenbergensis Fenchel \& 
Patterson, 1988 (Bicosoecales = Bicosoecida). Eur J Protistol 32: 216-226.

Otto, K., Weichart, D., and Kjelleberg, S. (1997) Plasmid transfer between marine Vibrio strains during predation by the heterotrophic microflagellate Cafeteria roenbergensis. Appl Environ Microbiol 63: 749-52.

Pasulka, A.L., Thamatrakoln, K., Kopf, S.H., Guan, Y., Poulos, B., Moradian, A., et al. (2018) Interrogating marine virus-host interactions and elemental transfer with BONCAT and nanoSIMS-based methods. Environ Microbiol 20: 671-692.

Pernthaler, J. (2005) Predation on prokaryotes in the water column and its ecological implications. Microbiology 3: 537-547.

Reed, L.J. and Muench, H. (1938) A simple method of estimating fifty per cent endpoints. Am J Epidemiol 27: 493-497.

Rostovtsev, V. V., Green, L.G., Fokin, V. V., and Sharpless, K.B. (2002) A stepwise Huisgen cycloaddition process: Copper(I)-Catalyzed regioselective "Ligation" of azides and terminal alkynes. Angew Chemie Int Ed 41: 2596-2599.

Saleh, A.M., Jacobson, K.R., Kinzer-Ursem, T.L., and Calve, S. (2019) Dynamics of non-canonical amino acid-labeled intra- and extracellular proteins in the developing mouse. Cell Mol Bioeng 12: 495-509.

Scheckenbach, F., Wylezich, C., Weitere, M., Hausmann, K., and Arndt, H. (2005) Molecular identity of strains of heterotrophic flagellates isolated from surface waters and deep-sea sediments of the South Atlantic based on SSU rDNA. Aquat Microb Ecol 38: 239-247.

Schoenle, A., Hohlfeld, M., Rosse, M., Filz, P., Wylezich, C., Nitsche, F., and Arndt, H. (2020) Global comparison of bicosoecid Cafeteria-like flagellates from the deep ocean and surface waters, with reorganization of the family Cafeteriaceae. Eur J Protistol 73: 125665.

Schramm, B. and Krijnse-Locker, J. (2005) Cytoplasmic organization of Poxvirus DNA replication. Traffic 6: 839-46.

Serwa, R.A., Sekine, E., Brown, J., Teo, S.H.C., Tate, E.W., and O'Hare, P. (2019) Analysis of a fully infectious bio-orthogonally modified human virus reveals novel features of virus cell entry. PLOS Pathog 15: e1007956.

Suzan-Monti, M., La Scola, B., Barrassi, L., Espinosa, L., and Raoult, D. (2007) Ultrastructural characterization of the giant volcano-like virus factory of Acanthamoeba polyphaga Mimivirus. PLoS One 2: e328.

Taylor, B.P., Weitz, J.S., Brussaard, C.P.D., and Fischer, M.G. (2018) Quantitative Infection Dynamics of Cafeteria Roenbergensis Virus. Viruses 10: 468.

Tornøe, C.W., Christensen, C., and Meldal, M. (2002) Peptidotriazoles on solid phase: [1,2,3]-Triazoles by regiospecific Copper(I)-catalyzed 1,3-dipolar cycloadditions of terminal alkynes to azides. J Org 
Chem 67: 3057-3064.

Ullrich, M., Liang, V., Chew, Y.L., Banister, S., Song, X., Zaw, T., et al. (2014) Bio-orthogonal labeling as a tool to visualize and identify newly synthesized proteins in Caenorhabditis elegans. Nat Protoc 9: 2237-2255.

Wang, F., Pan, H., Yao, X., He, H., Liu, L., Luo, Y., et al. (2020) Bioorthogonal metabolic labeling utilizing protein biosynthesis for dynamic visualization of nonenveloped enterovirus 71 infection. ACS Appl Mater Interfaces 12: 3363-3370.

Wisse, L.E., Penning, R., Zaal, E.A., van Berkel, C.G.M., ter Braak, T.J., Polder, E., et al. (2017) Proteomic and metabolomic analyses of vanishing white matter mouse astrocytes reveal deregulation of $E R$ functions. Front Cell Neurosci 11: 411.

Wulfmeyer, T., Polzer, C., Hiepler, G., Hamacher, K., Shoeman, R., Dunigan, D.D., et al. (2012) Structural organization of DNA in chlorella viruses. PLoS One 7: e30133.

Xiao, C., Fischer, M.G., Bolotaulo, D.M., Ulloa-Rondeau, N., Avila, G.A., and Suttle, C.A. (2017) Cryo-EM reconstruction of the Cafeteria roenbergensis virus capsid suggests novel assembly pathway for giant viruses. Sci Rep 7: 5484.

Zhang, J., Wang, J., Lee, Y.-M., Lim, T.-K., Lin, Q., and Shen, H.-M. (2017) Proteomic profiling of de novo protein synthesis in starvation-induced autophagy using bioorthogonal noncanonical amino acid tagging. Methods Enzymol 588: 41-59.

Zubkov, M. V. and Sleigh, M.A. (2000) Comparison of growth efficiencies of protozoa growing on bacteria deposited on surfaces and in suspension. J Eukaryot Microbiol 47: 62-69. 